\title{
A THEORY OF FINITELY DURABLE GOODS MONOPOLY with USED-GOODS MARKET and TRANSACTION COSTS
}

\author{
S. Huang* Y. Yang ${ }^{\dagger} \quad$ K. Anderson ${ }^{\ddagger}$
}

January, 2001

\begin{abstract}
We construct a dynamic game to model a monopoly of finitely durable goods. The solution concept is Markov perfect equilibria with general equilibria embedded in every time period. Our model is flexible enough to simultaneously explain or accommodate many commonly observed phenomena or stylized facts, such as concurrent leasing and selling, active secondary markets for used goods, heterogeneous consumers, endogenous consumption patterns, depreciation, an infinite time horizon, and non-trivial transaction costs. Within our model, consumers have incentives to segment themselves into various consumption classes according to their willingness to pay; and non-trivial transaction costs to sell used goods put strong constraints on consumers' consumption sequences in time. As a direct consequence of the finite durability the market power of the monopolist remains intact. Leasing manifests itself as a facilitator of price discrimination, by de-bundling the durable good into new and used portions that are naturally bundled together under outright sales. The concurrent leasing and selling reflects the degree of the comparative advantage the monopolist has over consumers in disposing used goods. This comparative advantage, which is partially exploited by the monopolist and partially shared by the consumers, provides a sufficient mechanism to gain Pareto improvement on the market.
\end{abstract}

\footnotetext{
*Ford Research Laboratory, shuang10@ford.com

${ }^{\dagger}$ Ford Research Laboratory, yyang1@ford.com

${ }^{\ddagger}$ Institute for Mathematics and its Applications, University of Minnesota, kanderso@ima.umn.edu
} 


\section{Introduction}

The nature of durable goods markets has long been an active research subject in economics. It is by now a well-known fact that intertemporal pricing of durable goods, even in a monopoly environment, is a subtle task. Two of the major issues initially are: First, how do used goods act as substitutes for new ones? Second, how can a monopoly sustain her monopoly power if her products have long durability? The difficulty of maintaining the monopoly power on durable goods is due in part to the problem of time-inconsistency, first pointed out by Coase(1972). Coase further conjectured that the monopoly will primarily rely on leasing to overcome the problem of time-inconsistency. This conjecture has been rigorously confirmed by Stokey (1981), Bulow (1982) and Gul, Sonnenschein and Wilson (1986) later on. However, drawing general conclusions is not easy. After the early confirmations of the Coase conjecture, other situations were described in which the Coase conjecture does not hold, such as in Bond and Samuelson (1984, 1987), Kahn (1986), Ausubel and Deneckere (1989), Bagnoli, Salant and Swierzbinski (1989), Karp (1996) and Kuhn (1998). Under alternative assumptions in these later works, it is no longer a certain that leasing always dominates over outright sale. It appears as if no general conclusions could be drawn, unless one is willing to confine the context of his or her investigation to a specific domain.

In addition to the high context-sensitivity in resolving those initial issues raised by Coase, new puzzles are starting to emerge and become commonly observable in real durable-good markets. For example, what we typically observe is concurrent selling and leasing. The new issues raised here are: First, for the monopolist, how should selling and leasing prices of new goods be determined, and under what conditions should scrappage be practiced? Second, for the consumers, how should they behave under various pricing schemes and different supplies of new and used goods? Finally, for the policymaker, who will ultimately benefit from concurrent selling and leasing? Although the prior works have substantially advanced our understanding of how durable goods markets function, they cannot effectively address these newly raised issues. One reason for this is that the economic assumptions involved in these prior works are often too idealized to accommodate the observed reality. For example, they often make one of the following assumptions: infinite durability, homogeneous consumers, exogenous consumer demand curves and no active secondary markets for used goods.

Some recent works have gone beyond these primitive assumptions. Rust (1986) solves for consumer behaviors and prices for used goods in a durable goods market, with stochastic 
depreciation. Anderson and Ginsburgh (1994), Waldman (1997) and Hendel and Lizzeri $(1997,1998,1999)$ study how adverse selection would affect the equilibrium in the usedgoods market and how the monopolist could benefit from explicitly interfering with the used-goods market, e.g., through imposing a variable transaction fee on buyers of used goods, or through practicing scrappage. Porter and Sattler (1999) introduce a transaction cost for private sellers of used goods, though the manufacturer in their model does not incur a disposal cost. Unfortunately, a common feature of all these works is that they do not address concurrent selling and leasing.

Bucovetsky and Chilton (1986) provide an early explanation of concurrent selling and leasing in a monopoly market, based on the threat of entry. Smith and Wakeman (1985) invoke an argument of comparative advantages for financial contracting costs to explain the same phenomenon. Hendel and Lizzeri (1998) illustrate, in a simple example, the coexistence of selling and leasing due to hidden information. However, this work does not systematically deal with the associated market structure. A direct interpretation without involving externality is provided by Desai and Purohit (1998), but their model is based on a two-period framework. In addition, one important aspect which has been largely ignored or not been emphasized enough by these works is that consumers' consumption decisions in the past have strong impacts on what they can do today. In other words, consumers also need to worry about time-consistency in their own decision-making. One reason for this kind of state-dependence is due to non-trivial transaction costs associated with selling used goods. To appropriately model consumer behaviors this aspect needs to be explicitly taken into account.

Given the timeliness to understand the durable goods markets, and the insufficient nature of the existing models, there is a need to construct a model, which adopts more realistic assumptions and can simultaneously explain or accommodate commonly observed phenomena or stylized facts, such as concurrent leasing and selling, active secondary markets, heterogeneous consumers, endogenous demands, depreciation and finite durability, and long or infinite time horizon. Constructing such a model will be the focus of this paper. Although it seems that all the ingredients in our model have been studied, often in isolation, in earlier works, our work is distinguished from others in that it unifies all these ingredients in a more comprehensive framework. Furthermore, this comprehensive framework allows us to achieve results that are not obvious and thus oftentimes untouched in the existing 


\section{literature.}

Nonetheless, the model is deterministic and operates in a monopoly setting. There is only a single product. Hidden information is only modeled implicitly through transaction costs. We hope to relax some of these limitations in our subsequent work. ${ }^{1}$ The remainder of the paper proceeds as follows. In section 2, we introduce the model in a general context. In section 3 , the concept of the solution is presented. In section 4 , the model is solved explicitly for a specific case. Many of the formal equations are explicitly verified in this section. The results presented in section 5 provide answers to those economic questions raised at the beginning of the introduction. We summarize the main messages of this work in the final section. In the appendix, we provide some details on several technical points used in the main text.

\section{The Model}

Time $t$ is measured discretely. The monopolist makes one product and faces no capacity constraints. All goods are of equal quality and have a lifetime of $N$ periods. All lease terms last one period. ${ }^{2}$ Goods depreciate deterministically over time and lease contracts do not contain an option. A consumer who would like to keep a leased good at the lease end simply purchases the used good from the used-good market at the prevailing used-good price. This is to say, all off-lease goods are returned to the manufacturer. ${ }^{3}$ We use superscripts to label time and subscripts to label other information, such as components of vectors.

Consumers: Consumers are assumed to live forever, and the population of consumers is a

\footnotetext{
${ }^{1}$ The model described here also provides us a framework to study valuation of real options in imperfect markets. This offers an opportunity to generalize the Black-Scholes-Merton approach, which is based on the concept of general equilibrium in competitive markets, to game theoretic environments in non-competitive markets with significant transaction costs. In a separate work, Huang and Yang (2000) explicitly examine the situation where used goods depreciate stochastically and consumers have the option to keep used goods at the lease end with given strike prices.

${ }^{2}$ Generally speaking, the manufacturer may want to exploit a variaty of lease terms. Within our framework these lease terms can be endogenized by introducing a lease price for every possible lease term. Doing that will substantially complicate the notation of the model. Since this issue does not arise in the case where we present the explicit solution in later sections, we will contend with the simplest non-trivial lease term here.

${ }^{3}$ This statement appears to be a presumption at this point. As a matter of fact, it will be shown later that this is a natural outcome of consumers' optimization in our particular setting.
} 
constant. As usual, the heterogeneity of consumers is represented by a type parameter $\theta$, whose distribution density function is denoted by $f(\theta)$ and cumulative distribution function by $F(\theta)$. Without loss of generality, we normalize $\theta$ such that $\theta \in[0,1]$ and $F(1)=1 .^{4}$ The action a consumer of type $\theta$ can take at time $t$ is represented by a $N+2$ dimensional binary vector, $a^{t}(\theta)=\left(b_{0}^{t}(\theta), \cdots, b_{N-1}^{t}(\theta), l_{0}^{t}(\theta=), i^{t}(\theta)\right)$. The interpretation of $b_{k}^{t}(\theta)=1$ (or $l_{0}^{t}(\theta)=1$ ) is that the consumer of type $\theta$ purchases a $k$-period old good (leases a new good) at time $t$. For convenience, we use $i^{t}(\theta)=1$ to imply that the consumer decides not to use any good at time $t$. The constraint $\sum_{k=0}^{N-1} b_{k}^{t}(\theta)+l_{0}^{t}(\theta)+i^{t}(\theta)=1$ is imposed for all $t$, to ensure that every consumer utilizes at most one good (new or used) during each time period.

Here we try to be as close to realistic situations as possible. Physical utilities are defined as utility flows, i.e. on a per period basis, whereas prices are defined as in their natural transaction contracts. The preference of a consumer of type $\theta$ is parameterized by the reservation price vector, $u(\theta)=\left(v_{0}(\theta), \cdots, v_{N-1}(\theta), w_{0}(\theta), 0\right)$, where $v_{k}(\theta)$ is the maximum the consumer is willing to pay for using a $k$-period old good (through purchasing) for one period, and $w_{0}(\theta)$ is the maximum for using a new good (through leasing) for one period. Because lease contracts do not contain an option, $v_{0}(\theta)$ should be identical to $w_{0}(\theta)$, since they both represent the monetary equivalence of the physical utility of using a new good for one period. ${ }^{5}$ The reservation price vector $u(\theta)$ is treated as exogenous and time independent. Its explicit functional form will be specified later. Finally, inaction implies a zero utility. The prices at time $t$ for goods at various ages are written as a $N+1$ dimension vector, $p^{t}=\left(q_{0}^{t}, \cdots, q_{N-1}^{t}, r_{0}^{t}\right)$, where $q_{k}^{t}$ is the price for purchasing a $k$-period old good for the remainder of its life span, and $r_{0}^{t}$ is the price for leasing a new good for one period.

If a consumer decides to sell a previously purchased good in the current time period, a transaction cost, $\alpha$, is incurred ${ }^{6}$ Here the transaction cost can be interpreted broadly. First,

\footnotetext{
${ }^{4}$ This normalization amounts to ignoring an overall constant factor that can depend on various attributes of the specific good under consideration, such as quality and durability. Since we treat the good as exogenous, in order to emphasize the market structure, this convenient normalization is appropriate.

${ }^{5}$ If leased goods are found to have a different depreciation rate from that of sold goods, as advocated by Desai and Purohit (1998), $v_{0}(\theta)$ and $w_{0}(\theta)$ have to be treated differently. This complication would introduce slight inconvenience for our model.

${ }^{6}$ More generally, consumers' transaction costs can be parameterized by a $(N+2) \times(N+2)$ matrix $\eta(\theta)=\left\{\eta_{k j}(\theta)\right\}$, where $\eta_{k j}(\theta)$ is the transaction cost of consumer $\theta$ when his decision sequence is represented by $a_{k}^{t}(\theta)=1$ and $a_{j}^{t-1}(\theta)=1$. For simplicity, we take $\alpha$ being independent of $\theta$.
} 
it represents the time and effort the consumer has to spend in order to sell the used good. Second, it embodies the value the consumer could get if he had perfect information about the used-goods market and full access to this market, and if the used-goods market were not plagued with adverse selection and moral hazard problems. The mangnitude of transaction cost could be inferred from trade-ins. If consumers trade-in their used goods, they can only expect less than what their dealers can sell the used goods for. The differences, often sizable, are both direct and indirect transaction costs paid implicitly by the consumers. ${ }^{7}$ Even so, these differences may still be underestimates of the true transaction costs that consumers would incur if they were to sell the used goods directly in the market.

Due to the non-trivial transaction costs incurred in selling used goods, consumers' consumption decisions are state dependent. As a result, consumers, as well as the monopolist, need to seek time-consistency in their own intertemporal consumption decisions. For example, if $\alpha$ is sufficiently high, a consumer who purchases a good in this period is locked-in for the next period. By construction, the payoff per period at time $t$ for consumer $\theta$ depends on the current action vector, current price vector, as well as the action vector from the previous period, i.e. $\Pi_{\theta}=\Pi_{\theta}\left[a^{t-1}(\theta), a^{t}(\theta), p^{t}\right]$. This implies that the dynamics will be Markovian.

The Manufacturer: The monopolistic manufacturer is assumed to have a constant marginal cost, $c$, in her production technology. The manufacturer also incurs a disposal cost, $\beta$, to sell each returned off-lease good on the used-goods market. It is natural to expect that the manufacturer is more efficient in disposing a used good than any individual consumer. ${ }^{8}$ This is because the manufacturer has better market information, better market access and a larger scale of economy. Furthermore, the manufacturer is likely to suffer less from adverse selection, since it is easier to hold a big firm accountable for her actions. In addition, there are ways to alleviate problems associated with hidden information through explicit transaction costs, such as issuing warranties. Lastly, it is also natural to expect that all transaction costs are small. Therefore, the following conditions should hold

$$
0<\beta<\alpha \ll 1
$$

\footnotetext{
${ }^{7}$ Our assertion is certainly counter to the argument that trade-in can solve the illiquidity problem of used-goods markets. Also, see Smith and Wakeman (1985) for an economic justification of transaction cost.

${ }^{8}$ Even though Smith and Wakeman (1985) believe that the comparative advantage of the manufacturer in disposing used goods by itself is insufficient to result in a concurrent selling and leasing, as we show later, it is the difference of the two transaction costs supplemented by the segmentation of consumers that provides a sufficient mechanism.
} 
where the rightmost inequality is due to our normalization of $\theta$.

There are three parts in the revenue stream of the manufacturer: sale of new goods, lease of new goods, and sale of returned off-lease goods. These three parts in turn depend on the aggregate consumer behaviors in the current and previous periods. In particular, the populations of consumers who leased new good one period earlier and who purchase and lease new good in the current period are given respectively by

$$
\left(L_{0}^{t-1}, B_{0}^{t}, L_{0}^{t}\right)=\int_{0}^{1} d \theta f(\theta)\left(l_{0}^{t-1}(\theta), b_{0}^{t}(\theta), l_{0}^{t}(\theta)\right)
$$

So the profit function per period for the manufacturer at time $t$ is given by

$$
\Pi\left[L_{0}^{t-1}, B_{0}^{t}, L_{0}^{t}, p^{t}\right]=\left(q_{0}^{t}-c\right) B_{0}^{t}+\left(r_{0}^{t}-c\right) L_{0}^{t}+\left(q_{n}^{t}-\beta\right) L_{0}^{t-1}
$$

For now, we also assume that no used goods are scrapped by the manufacturer. A generalization to the case with scrappage will be given in the later part of the paper.

Rules of the Game: As in any standard game, all the players in our model are assumed to be rational and to maximize their own net present values (with a common discount factor $0<\rho \leq 1)$. All the cost and preference information are common knowledge, and there is no hidden information. We limit the strategy space for all the players to be pure Markov strategies. Behavior strategies, or mixed strategies, are not expected to play a significant role in the model, because the set of indifferent consumers has measure zero. Therefore, we do not consider these strategies.

The control variables for the manufacturer in each period are the prices for new goods, $q_{0}^{t}$ and $r_{0}^{t}$. We assume that the used-goods market is competitive, and thus the prices for used goods, $q_{k}^{t}$ with $0<k<N$, will be implicitly determined. This assumption also implies that clearance conditions will equalize the demand and supply of used goods of each age at all times. The reasons for treating the used-goods market differently from the new-goods market are as follows. 1) The manufacturer typically sells off-lease goods through auctions and 2) the manufacturer also faces the threat of potential entry from those consumers who could have become used-goods sellers.

The timing of the game is such that the manufacturer picks new sale and lease prices at the beginning of each period. These prices are immediately announced. Consumers, who are price takers, play the game strategically against the manufacturer, but not against each other. Each consumer's action at time $t$ only depends on his own action in the previous 
period and announced $q_{0}^{t}$ and $r_{0}^{t}$. The aggregate consumer actions and the used-good prices need to be consistent with the clearance conditions of the used-goods market.

The above process is repeated forever. The infinite time horizon will allow us to analyze the long run behaviors of the manufacturer and consumers, and to alleviate the adverse effects of otherwise artificially specified terminal conditions.

\section{Concept of the Solution}

We take the standard approach to solve the time-consistency problem by only considering Nash equilibria that are subgame perfect. However, the solution concept proposed in this paper is slightly more involved than the standard Markov perfect equilibrium defined in Maskin and Tirole (1988a, 1988b). This is because we now have a competitive used-good market that needs to be cleared in every time period. Therefore, our dynamic game equilibrium has a general equilibrium embedded at every stage. In addition, we are dealing with a situation that is highly asymmetric compared to the familiar situation of oligopoly or to the situation of homogeneous consumers. In the context of oligopoly, the Bellman equations are often similar, if not symmetric, in structure for various firms. When consumers are homogeneous, the seller's decision is complementary to that of the consumers. This often results in one Bellman's equation, such as in Ausubel and Deneckere (1989) and Karp (1996).

In order to better understand the dynamic game we have described, we next establish a formal mathematical framework. This framework will take the form of a pair of Bellman equations, one for the manufacturer and the other for consumer $\theta$. This formalism allows us to systematically make statements about the actions of the players in a more general context. Later we will solve the Bellman equations in a specific case.

The Consumers' Bellman Equation: The Bellman equation for consumer $\theta$ is derived through backward induction. The process of dynamic programming automatically guarantees that solutions to these equations possess the subgame perfection we require. The net present value functions in the equations are labeled by the state vectors that completely specify the information necessary for rational decision-making.

For a consumer of type $\theta$, it is relatively straightforward to see that the net present value 
function has the form of $V_{\theta}^{t}\left[a^{t-1}(\theta), p^{t}\right]$, which satisfies the following Bellman equation

$$
V_{\theta}^{t}\left[a^{t-1}(\theta), p^{t}\right]=\max _{a^{t}(\theta)}^{\prime}\left\{\Pi_{\theta}\left[a^{t-1}(\theta), a^{t}(\theta), p^{t}\right]+\rho V_{\theta}^{t+1}\left[a^{t}(\theta), p^{t+1}\right]\right\} .
$$

Although the maximization in the above equation treats all components in $p^{t}$ as given by the individual consumer, the prime serves to remind that the used-goods prices are such that the market is cleared (see section 3 ). Furthermore, the price vector $p^{t+1}$ needs to be replaced by the appropriate reaction functions, which will be specified shortly. The optimal action vector from the above equation, $a^{t}(\theta)^{*}$, is the reaction function of the consumer to the price vector $p^{t}$, given his previous action $a^{t-1}(\theta)$,

$$
R_{\theta}^{t}\left[a^{t-1}(\theta), p^{t}\right]=a^{t}(\theta)^{*}
$$

It is helpful to view $R_{\theta}^{t}\left[a^{t-1}(\theta), p^{t}\right]$ as the transition matrix for a consumer of type $\theta$ from his previous action $a^{t-1}(\theta)$ to the current action $a^{t}(\theta)^{*}$, when the price vector $p^{t}$ is given.

The Manufacturer's Bellman Equation: The manufacturer's net present value function cannot be labeled by the payoff-relevant aggregate information alone. More detailed information is necessary to specify the complete equilibrium path. In order to derive the manufacturer's Bellman equation we need to introduce another vector

$$
g^{t}(\theta)=\left(g_{0}^{t}(\theta), \cdots, g_{N-1}^{t}(\theta), g_{N}^{t}(\theta), g_{N+1}^{t}(\theta)\right)
$$

The interpretation of this vector is as follows: $g_{k}^{t}(\theta)$, with $0 \leq k<N$, is the percentage of consumers in the interval $(\theta, \theta+d \theta)$ who buy (or possess) $k$-period old goods at time $t-1$. $g_{N}^{t}(\theta)$ and $g_{N+1}^{t}(\theta)$ are the percentages of consumers in the same type interval who lease new goods and do not use any goods at time $t-1$ respectively. As such, every component of $g^{t}(\theta)$ is non-negative and the sum over all components is one.

Next, the total numbers of consumers who purchase and lease new goods at time $t-1$ and $t$ are related to $g^{t}(\theta)$ and $g^{t+1}(\theta)$ in the following way:

$$
\left(L_{0}^{t-1}, B_{0}^{t}, L_{0}^{t}\right)=\int_{0}^{1} d \theta f(\theta)\left(g_{N}^{t}(\theta), g_{0}^{t+1}(\theta), g_{N}^{t+1}(\theta)\right) .
$$

The evolution of $g^{t}(\theta)$ is governed by the reaction functions for consumers

$$
g^{t+1}(\theta)=\sum_{k=0}^{N+1} R_{\theta}^{t}\left[a_{k}^{t-1}(\theta)=1, p^{t}\right] g_{k}^{t}(\theta) .
$$


Now the Bellman equation for the manufacturer can be written as

$$
V^{t}\left[g^{t}(\theta)\right]=\max _{q_{0}^{t}, r_{0}^{t}}\left\{\Pi\left[L_{0}^{t-1}, B_{0}^{t}, L_{0}^{t}, p^{t}\right]+\rho V^{t+1}\left[g^{t+1}(\theta)\right]\right\} .
$$

The optimal prices for new goods, $q_{0}^{t *}$ and $r_{0}^{t *}$, solved from the Bellman equation for the manufacturer are called the reaction functions of the manufacturer to its state vector

$$
R_{0}^{t}\left[g^{t}(\theta)\right]=q_{0}^{t *}, \quad \text { and } \quad R_{L}^{t}\left[g^{t}(\theta)\right]=r_{0}^{t *}
$$

Clearance Conditions: To specify clearance conditions for the used-goods market we first express the total number of new goods at time $t$ as $P_{0}^{t}=B_{0}^{t}+L_{0}^{t}$, and the total number of used goods of age $k$ at time $t$ as $P_{k}^{t}=\int_{0}^{1} d \theta f(\theta) g_{k}^{t+1}(\theta)$ with $0<k<N$. Then the $N-1$ clearance conditions at time $t$ are given by

$$
P_{k}^{t-1}=P_{k+1}^{t} \quad \text { for } \quad 0 \leq k<N-1
$$

from which the $N-1$ used-goods prices, $q_{k}^{t}$ with $1 \leq k<N$, are solved for. These clearance conditions will be modified when some of the used goods are scrapped. If we denote usedgood prices that clear the used-goods markets by $q_{k}^{t *}$, we can view these prices as the reaction functions of the consumers collectively

$$
R_{k}^{t}\left[g^{t}(\theta), q_{0}^{t}, r_{0}^{t}\right]=q_{k}^{t *} \quad \text { for } \quad 1 \leq k \leq N-1
$$

Finally, let us come back to the Bellman equation for the consumer of type $\theta$. The price vector $p^{t+1}$ in Eq.(4) should be replaced by $(\tau=t+1)$

$$
p^{\tau} \longrightarrow\left(R_{0}^{\tau}\left[g^{\tau}(\theta)\right], R_{1}^{\tau}\left[g^{\tau}(\theta), q_{0}^{\tau}, r_{0}^{\tau}\right], \cdots, R_{N-1}^{\tau}\left[g^{\tau}(\theta), q_{0}^{\tau}, r_{0}^{\tau}\right], R_{L}^{\tau}\left[g^{\tau}(\theta)\right]\right)
$$

To summarize, finding the Markov perfect equilibrium solution of the model amounts to solving for various reaction functions, defined in Eq.(5), Eq.(10) and Eq.(12), from the highly asymmetric, coupled Bellman equations in Eq.(4) and Eq.(9),with the clearance conditions Eq.(11) as constraints in every time period. The consumer's optimization is a finite dimensional dynamic programming problem, and the manufacturer's optimization is an infinite dimensional dynamic programming problem.

Steady Limit: A Markov perfect equilibrium in the infinite time horizon of an autonomous system such as ours is a solution in which all the explicit time dependence has dropped 
out. However, cyclic behaviors, such as the Edgeworth cycles found in Maskin and Tirole (1988b), are allowed for $g^{t}(\theta)$ and $p^{t}$. We will focus on an equilibrium that has a true steady limit, i.e., an equilibrium in which all the prices and aggregate consumer behaviors are constant in time. In this equilibrium, the game converges in a finite number of periods to a fixed point in the strategy space for all players starting from a given initial state. ${ }^{9}$ If one such point is more natural than any other steady limits in the game, this point will be called focal point, analogous to the concept of the focal price in Maskin and Tirole (1988b).

The Bellman equations in the steady limit are drastically simplified, since all the explicit time dependences drop out. In particular, the fixed point can be characterized by a pair of vectors, $g^{*}(\theta)$ and $p^{*}$, such that the following self-consistency conditions are met

$$
\begin{aligned}
g^{*}(\theta) & =\sum_{k=0}^{N+1} R_{\theta}\left[a_{k}(\theta)=1, p^{*}\right] g_{k}^{*}(\theta) \\
p^{*} & =\left(R_{0}\left[g^{*}(\theta)\right], R_{1}\left[g^{*}(\theta), q_{0}^{*}, r_{0}^{*}\right], \cdots, R_{L}\left[g^{*}(\theta)\right]\right)
\end{aligned}
$$

In addition, $g^{*}(\theta)$ and $p^{*}$ satisfy the Bellman equations at the focal point

$$
\begin{aligned}
V_{\theta}\left[a(\theta), p^{*}\right] & =\Pi_{\theta}\left[a(\theta), R_{\theta}\left[a(\theta), p^{*}\right], p^{*}\right]+\rho V_{\theta}\left[R_{\theta}\left[a(\theta), p^{*}\right], p^{*}\right] \\
V\left[g^{*}(\theta)\right] & =\Pi\left[L_{0}\left[g^{*}(\theta)\right], B_{0}\left[g^{*}(\theta)\right], L_{0}\left[g^{*}(\theta)\right], p^{*}\right]+\rho V\left[g^{*}(\theta)\right]
\end{aligned}
$$

This last equation immediately implies that the optimization problem in the steady limit for the monopolist effectively becomes static.

Up until this point, no attempt has been made to address questions such as the conditions under which a Markov perfect equilibrium exists, whether or not the model possesses multiple equilibria, and so on. These questions will be partially answered later in a more specific context. Furthermore, many of these formal conditions set up in this section will be explicitly verified in examples we consider in later parts of the paper.

\section{Explicit Solution for the Case of $N=2$}

Now let us consider the simplest non-trivial case: $N=2$. We normalize the physical utility of the good for its entire life span to be 1 . Then the following functional form of the reservation price (or utility flow) vector for consumers is chosen: $v_{0}(\theta)=(1-\delta) \theta$,

\footnotetext{
${ }^{9}$ It is possible that the space of initial conditions can be categorized into regions that are analogous to the concept of ergodic classes introduced in Maskin and Tirole (1988b).
} 
$v_{1}(\theta)=\delta \theta$ and $w_{0}(\theta)=v_{0}(\theta)$, with $\delta<1 / 2$, reflecting the fact that a new good is more desirable than a used one. In addition, we assume a uniform distribution for the reservation prices of consumers: $f(\theta)=1{ }^{10}$ With this parameterization the full payoff matrix for consumer $\theta$ is given in Table 1 . We start by first constructing the focal point and then showing how the focal point can be induced by the monopolist from an initial state. ${ }^{11}$ To make the remaining presentation concise, the condition

$$
\alpha<q_{1}
$$

will be imposed throughout. This condition implies that selling a used good is prefered than wasting (not consuming) it.

Table 1: The payoff matrix for consumer $\theta$ with $N=2$ and $n=1$

\begin{tabular}{||c||c|c|c|c||}
\hline \hline & $b_{0}^{t-1}(\theta)$ & $b_{1}^{t-1}(\theta)$ & $l_{0}^{t-1}(\theta)$ & $i^{t-1}(\theta)$ \\
\hline \hline$b_{0}^{t}(\theta)$ & $(1-\delta) \theta-q_{0}^{t}+q_{1}^{t}-\alpha$ & $(1-\delta) \theta-q_{0}^{t}$ & $(1-\delta) \theta-q_{0}^{t}$ & $(1-\delta) \theta-q_{0}^{t}$ \\
\hline$b_{1}^{t}(\theta)$ & $\delta \theta$ & $\delta \theta-q_{1}^{t}$ & $\delta \theta-q_{1}^{t}$ & $\delta \theta-q_{1}^{t}$ \\
\hline$l_{0}^{t}(\theta)$ & $(1-\delta) \theta-r_{0}^{t}+q_{1}^{t}-\alpha$ & $(1-\delta) \theta-r_{0}^{t}$ & $(1-\delta) \theta-r_{0}^{t}$ & $(1-\delta) \theta-r_{0}^{t}$ \\
\hline$i^{t}(\theta)$ & $q_{1}^{t}-\alpha$ & 0 & 0 & 0 \\
\hline \hline
\end{tabular}

\subsection{Consumer Behaviors at the Focal Point}

Since we are interested in the focal point, the time label will be dropped from the price vector. Let N, U, L and I denote a single period action, corresponding to purchasing a new good, purchasing a used good, leasing a new good, and not using any good respectively.

The following lemma characterizes consumption patterns that can emerge when the price vector is constant.

Lemma 1 There are at most five consumer strategy patterns at any given constant price vector: always lease new goods (denoted by $L L$ ); always purchase new goods (denoted by

\footnotetext{
${ }^{10}$ Generalizations to an arbitrary $f(\theta)$ is trivial, as long as the corresponding $F(\theta)$ is strictly increasing. Since there is no additional insights can be gained with an arbitrary $f(\theta)$, we prefers $f(\theta)=1$ for expositional clarity.

${ }^{11}$ There is no known procedure for solving coupled Bellman equations. Thus we need to proceed by explicitly constructing the solution. The solution is then verified by checking if the appropriate conditions are satisfied.
} 
NN); purchase new goods when they have nothing left from the previous period or continue to use their previously owned goods (denoted by NU); always purchase used goods (denoted by UU) and do not participate (denoted by II).

Proof: See Appendix A.1. Q.E.D.

Since the manufacturer has the market power to control prices for new goods, we anticipate that the space spanned by $\left(q_{0}, q_{1}, r_{0}\right)$ will be divided into regions from the point of view of profit maximization. One condition that arises with this consideration is

$$
q_{0}-q_{1}<r_{0}<q_{0}-q_{1}+\alpha
$$

whose justification is provided by Lemma 2 in the next subsection. Intuitively, this condition guarantees that the monopolist will not end up using suboptimal strategies, such as pure selling or pure leasing.

We further anticipate that consumers are segmented into various consumption classes according to their willingness to pay for the good. Those who are willing to pay the most for the good (i.e. have the highest $\theta$ value) will fall into class LL. Those with next highest $\theta$ values belong to NU, and then to UU. Those with the lowest $\theta$ values are in class II. The class division points are found by setting the net present value functions in adjacent regions equal to each other. This is formalized in the following proposition.

Proposition 1 As long as $q_{0}, q_{1}$ and $r_{0}$ are such that the condition Eq.(19) is satisfied, and the ordering $0 \leq \theta_{3} \leq \theta_{2} \leq \theta_{1} \leq 1$ is maintained, consumers in $\left(\theta_{1}, 1\right)$ will follow $L L$; consumers in $\left(\theta_{2}, \theta_{1}\right)$ will follow $N U$; consumers in $\left(\theta_{3}, \theta_{2}\right)$ will follow UU; and consumers in $\left(0, \theta_{3}\right)$ will follow II. More specifically, consumers' reaction function is completely characterized as follows:

$$
R_{\theta}[a, p]= \begin{cases}R_{\theta}\left[^{*}, p\right]=(0,0,1,0)=L & \text { when } \theta \in\left(\theta_{0}, 1\right), \\ R_{\theta}[N, p]=(0,1,0,0)=U & \text { when } \theta \in\left(\theta_{1}, \theta_{0}\right), \\ R_{\theta}[\bar{N}, p]=(0,0,1,0)=L & \text { when } \theta \in\left(\theta_{1}, \theta_{0}\right), \\ R_{\theta}[N, p]=(0,1,0,0)=U & \text { when } \theta \in\left(\theta_{2}, \theta_{1}\right), \\ R_{\theta}[\bar{N}, p]=(1,0,0,0)=N & \text { when } \theta \in\left(\theta_{2}, \theta_{1}\right), \\ R_{\theta}\left[{ }^{*}, p\right]=(0,1,0,0)=U & \text { when } \theta \in\left(\theta_{3}, \theta_{2}\right), \\ R_{\theta}[N, p]=(0,1,0,0)=U & \text { when } \theta \in\left(\theta_{4}, \theta_{3}\right), \\ R_{\theta}[\bar{N}, p]=(0,0,0,1)=I & \text { when } \theta \in\left(\theta_{3}, \theta_{2}\right), \\ R_{\theta}[*, p]=(0,0,0,1)=I & \text { when } \theta \in\left(0, \theta_{4}\right),\end{cases}
$$


where * can be any of $N, U, L, I$, and $\bar{N} \in\{L, U, I\}$; The class division points are given by $\theta_{0}=\min \left\{1,\left(r_{0}-q_{1}+\alpha\right) /(1-2 \delta)\right\}, \theta_{1}=\left[(1+\rho) r_{0}-q_{0}\right] /[\rho(1-2 \delta)], \theta_{2}=\left[q_{0}-(1+\rho) q_{1}\right] /(1-2 \delta)$, $\theta_{3}=q_{1} / \delta$, and $\theta_{4}=\max \left\{0,\left(q_{1}-\alpha\right) / \delta\right\}$.

Proof: It is easy to see that class NN is dominated by class LL, as long as $r_{0}<q_{0}-q_{1}+\alpha$ and $\beta<\alpha$. In other $=$ words, self-replicated leases are not as attractive as the leases offered by the manufacturer.

With the remaining four classes: LL, NU, UU, II, we can explicitly construct the net present value functions at the focal point for the optimal consumption patterns as follows,

$$
\begin{array}{llll}
V_{\theta}[\mathrm{L}, p] & =\frac{(1-\delta) \theta-r_{0}}{1-\rho} & \text { when } & \theta \in\left(\theta_{1}, 1\right) \quad \text { or } \theta \in \mathrm{LL} \\
V_{\theta}[\mathrm{N}, p] & =\frac{\delta \theta+\rho\left[(1-\delta) \theta-q_{0}\right]}{1-\rho^{2}} & \text { when } \theta \in\left(\theta_{2}, \theta_{1}\right) \quad \text { or } \theta \in \mathrm{NU} \\
V_{\theta}[\mathrm{U}, p] & =\frac{(1-\delta) \theta-q_{0}+\rho \delta \theta}{1-\rho^{2}} & \text { when } \theta \in\left(\theta_{2}, \theta_{1}\right) \quad \text { or } \theta \in \mathrm{NU} \\
V_{\theta}[\mathrm{U}, p] & = & & \text { when } \theta \in\left(\theta_{3}, \theta_{2}\right) \quad \text { or } \theta \in \mathrm{UU} \\
V_{\theta}[\mathrm{I}, p] & \frac{\delta \theta-q_{1}}{1-\rho} & \text { when } \theta \in\left(0, \theta_{3}\right) \quad \text { or } \theta \in \mathrm{II}
\end{array}
$$

These net present value functions and the consumer classes are also illustrated in Figure 1. We can now explicitly verify that the above consumer behavior is the solution to the finite dimensional dynamic programming problem in Eq.(16), which is known to possess a unique solution, see for example Bertsekas (1995). We will not present the verification process here, since it is lengthy but straightforward. Q.E.D.

At given $q_{0}$ and $r_{0}$, the used-good price that clears the used-good market can be obtained from solving the clearance condition given by equating the numbers of consumers in classes LL and UU. This is equivalent to

$$
1-\theta_{1}=\theta_{2}-\theta_{3}
$$

which in turn yields

$$
q_{1}^{*}\left(q_{0}, r_{0}\right)=\frac{\delta\left[(1+\rho) r_{0}-(1-\rho) q_{0}-\rho(1-2 \delta)\right]}{\rho[1-\delta(1-\rho)]} .
$$




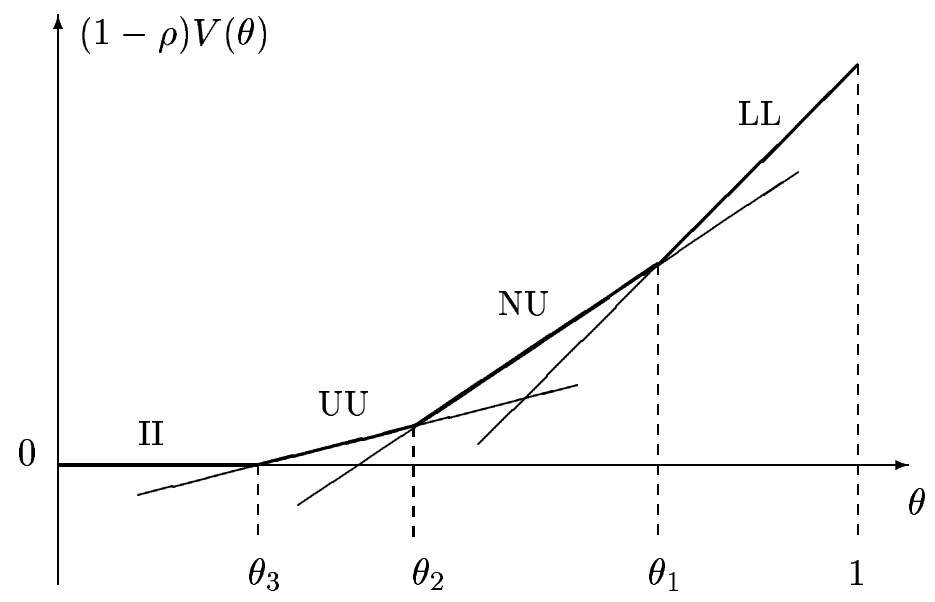

Figure 1: Net present value functions for consumers at the limit of $\rho \rightarrow 1$ as functions of their types labeled by $\theta$.

Finally, it is also straightforward to check that the fixed point condition in Eq.(14) is satisfied by the state vector, $g^{*}(\theta)$, at the focal point ${ }^{12}$

$$
g^{*}(\theta)= \begin{cases}(0,0,1,0) & \text { when } \theta \in\left(\theta_{1}, 1\right), \\ (1 / 2,1 / 2,0,0) & \text { when } \theta \in\left(\theta_{2}, \theta_{1}\right), \\ (0,1,0,0) & \text { when } \theta \in\left(\theta_{3}, \theta_{2}\right), \\ (0,0,0,1) & \text { when } \theta \in\left(0, \theta_{3}\right) .\end{cases}
$$

\subsection{Monopolist Behavior at the Focal Point}

The expressions for population sizes of those who purchase and lease new goods at the focal point per period are

$$
B_{0}\left[q_{0}, r_{0}\right]=\frac{\theta_{1}-\theta_{2}}{2}=\frac{(1+\rho)\left[r_{0}-q_{0}+\rho q_{1}^{*}\left(q_{0}, r_{0}\right)\right]}{2 \rho(1-2 \delta)}
$$

\footnotetext{
${ }^{12}$ There are actually an infinite number of choices of $g^{*}(\theta)$ that could satisfy the same set of conditions. In particular, the only necessary requirement is that $g^{*}(\theta)$ in the interval of $\theta \in\left(\theta_{2}, \theta_{1}\right)$ be integrated to $(1 / 2,1 / 2,0,0)\left(\theta_{1}-\theta_{2}\right)$. This degeneracy, which has no effect on the profit function of the manufacturer, can be lifted if we further demand that the focal point be reached from a specific initial state by following a specific path. See also subsection A.3.
} 


$$
L_{0}\left[q_{0}, r_{0}\right]=1-\theta_{1}=\frac{q_{0}-(1+\rho) r_{0}+\rho(1-2 \delta)}{\rho(1-2 \delta)} .
$$

After eliminating the used-good price using Eq.(27), these populations will only depend explicitly on the control variables of the monopolist, $q_{0}$ and $r_{0}$.

Lemma 2 To maximize her profit at the focal point, the monopolist will set the prices for new goods such that the condition in Eq.(19) is satisfied.

Proof: See Appendix A.2. Q.E.D.

From now on we will only present results with the discount factor for consumers $\rho=1$. Although the analysis is no harder with a general $\rho$, many algebraic expressions become too cumbersome and in general are not instructive. No significant insights are lost, as long as $\rho$ for consumers is sufficiently close to one. Any qualitative effects of $\rho<1$ for consumers will be noted in the text. Results with $\rho=1$ are equivalent to the results of assuming that consumers are maximizers of average payoffs per period. This is sometimes referred to as the time-average criterion.

Proposition 2 There is a critical disposal cost for the manufacturer

$$
\beta_{c}=\frac{(1-c)(1-2 \delta)}{2} .
$$

When $0<\beta<\beta_{c}$ a leasing program is profitable and four classes (LL, NU, UU and II) are induced by the manufacturer. In this case, $q_{0}^{*}$ and $r_{0}^{*}$ are interior solutions given by

$$
q_{0}^{*}=\frac{1+c}{2}, \quad q_{1}^{*}=\delta \frac{c+\beta+2 \delta}{1+2 \delta}, \quad r_{0}^{*}=q_{0}^{*}-q_{1}^{*}+\frac{\beta}{2} \cdot{ }^{13}
$$

When $\beta \geq \beta_{c}$ a leasing program is not profitable and only two classes (NU and II) are induced by the manufacturer. $q_{0}^{*}$ is still an interior solution, but $r_{0}^{*}$ is a run-away solution, given by

$$
q_{0}^{*}=\frac{1+c}{2}, \quad q_{1}^{c} \equiv \delta \frac{1+c}{2}, \quad r_{0}^{*}>r_{0}^{c} \equiv q_{0}^{*}-q_{1}^{c}+\frac{\beta_{c}}{2} \cdot{ }^{14}
$$

\footnotetext{
${ }^{13}$ The inequality $r_{0}^{*}>q_{0}^{*}-q_{1}^{*}$ implies that consumers in UU can have potential arbitrage oppurtunities. They could buy new goods and immediately lease them to consumers in LL and retain off-leave goods for their own consumption. This kind of opportunity can be prevented by assuming a transaction cost that is greater than $\beta / 2$ for an individual to lease one new good to another individial, as our model explicitly constrains that every consumer can at most buy one new good in each period. Otherwise, any effect due to institutional lessors, such as banks, needs to be explicitly modeled.

${ }^{14}$ Here $q_{1}^{c}$ and $r_{0}^{c}$ are in the sense of Kuhn-Tucker, and should be understood as the values beyond which no consumers are willing to be in classes LL and UU.
} 
Proof: The manufacturer's optimization at the focal point is equivalent to a static profit maximization. (See Eq.(17).) The profit function for the monopolist at the focal point can be explicitly constructed using Eqs.(27-30). Then the results are obtained by maximizing the profit function with respect to $q_{0}$ and $r_{0}$, subject to the constraint $0 \leq \theta_{3} \leq \theta_{2} \leq \theta_{1} \leq 1$, through the standard optimization procedure, such as the Kuhn-Tucker method. Q.E.D.

Here $\beta_{c}$ can be interpreted intuitively. The factor $(1-c)$ is the maximum margin that the manufacturer can ever get. When the marginal cost is high, leasing is less likely to be profitable. The factor $(1-2 \delta)$ implies, on the other hand, that when used goods are close substitutes to new ones (or $\delta \approx 1 / 2$ ), the window of leasing is very small. Generally, $\beta_{c}$ can be a significant portion of $q_{0}^{*}$. So, in many realistic situations the producer's profit can increase when she chooses to implement a leasing program. When $\beta<\beta_{c}$, the corresponding populations in each class are,

15

$$
P_{\mathrm{LL}}^{*}=\frac{1-c}{2(1+2 \delta)}-\frac{\beta}{1-4 \delta^{2}}, \quad P_{\mathrm{NU}}^{*}=\frac{\beta}{1-2 \delta}, \quad P_{\mathrm{UU}}^{*}=P_{\mathrm{LL}}^{*} .
$$

The optimal profit per period is

$$
\Pi\left[L_{0}^{*}, B_{0}^{*}, L_{0}^{*}, p^{*}\right]=\frac{(1-c-\beta)^{2}}{4(1+2 \delta)}+\frac{\beta^{2}}{4(1-2 \delta)} \cdot{ }^{16}
$$

When $\beta \geq \beta_{c}$, the corresponding populations in each class are,

$$
P_{\mathrm{LL}}^{*}=0, \quad P_{\mathrm{NU}}^{*}=\frac{1-c}{2}, \quad P_{\mathrm{UU}}^{*}=P_{\mathrm{LL}}^{*},
$$

and the optimal profit per period is

$$
\Pi\left[L_{0}^{*}, B_{0}^{*}, L_{0}^{*}, p^{*}\right]=\frac{(1-c)^{2}}{8} .
$$

As the disposal cost increases from 0 to $\beta_{c}$, the profit per period of the monopolist decreases from $(1-c)^{2} /(4+8 \delta)$ monotonically to $(1-c)^{2} / 8$. The ratio of these two limits is $2 /(1+2 \delta)$. This can be substantial as long as $\delta$ is not too close to one-half.

\footnotetext{
${ }^{15}$ In realistic situations, $\beta$ is very small relative to $q_{0}^{*}$. This does not imply that $P_{\mathrm{NU}}^{*}$ is small, because it is magnified by a factor of $1 /(1-2 \delta)$. On the other hand, $P_{\mathrm{NU}}^{*}$ would not be divergent as $\delta \rightarrow 1 / 2$, since $\beta_{c}$ contains a factor of $(1-2 \delta)$.

${ }^{16}$ It may be tempting to literally use this expression to infer that the monopolist prefers a depreciation $\delta \rightarrow 0$. The problem with this erroneous inference is due to our normalization convention: $F[1]=1$. A full optimization with respect to $\delta$ requires treating $F[1]$ as an explicit function of $\delta$.
} 
When the general discount value is introduced, the tendency is for more consumers to choose class LL. For example, when $\rho<1$, there is another small region of $\beta$ near the origin where three classes (LL, UU and II) are induced. The size of this region shrinks to zero as $\rho$ approaches 1 .

\subsection{Beyond the Focal Point}

So far, we have been concentrating on the focal point. But the focal point is only a single point in the strategy space, representing a long run limit on an equilibrium path. The focal point only solves the time independent Bellman equations in section 3. In principle, the formalism in section 3 would have specified all the equilibrium paths as the complete solution to the full Bellman equations derived in that section. Unfortunately, there is no known general procedure for solving these equations. Even to specify an arbitrary initial state for the manufacturer would be rather cumbersome, since there are an infinite number of $g^{1}$ vectors, one for every $\theta$. However, this does not mean that our approach is only valid in the steady limit. By directly using backward induction, it is still possible to solve for some of the equilibrium paths beyond the focal point within the framework. How this can be done is illustrated in a specific example in A.3.

\subsection{A Comment on Uniqueness}

The equilibrium that contains the focal point constructed so far is not unique, even if we ignore the degeneracy mentioned in footnote 12. Other steady limits of distinct equilibria can be constructed. Table 2 provides two such examples, corresponding to the cases of pure leasing and pure selling. It can be verified that these additional steady limits are Pareto dominated in aggregate by the one with concurrent leasing and selling. ${ }^{17}$ This is why we call the steady limit with concurrent leasing and selling a focal point. It is also conceivable that cyclic solutions, analogous to the Edgeworth cycle solutions found in Maskin and Tirole (1988b), may also exist in the model. ${ }^{18}$

\footnotetext{
${ }^{17}$ It is not generally true, however, that every consumer benefits from leasing. As can be checked explicitly from the expressions in Table 2, when self-replicated leasing is feasible, some consumers in class NU would be worse off, essentially due to the fact that $q_{0}^{*}$ is slightly lower without leasing than with leasing.

${ }^{18}$ Villas-Boas (2000) finds price cycles supported by Markov perfect equilibria in an interesting model that has a different context from ours.
} 
Table 2: The cases of pure leasing and pure selling

\begin{tabular}{||c||c|c||}
\hline \hline & pure leasing & pure selling \\
\hline \hline classes & $\mathrm{LL}, \mathrm{UU}, \mathrm{II}$ & $\mathrm{NU}, \mathrm{UU}, \mathrm{II}$ \\
\hline requisite & $\beta<\alpha$ & $\beta<\alpha<(1-c)(1-\sqrt{\delta+1 / 2}) \equiv \alpha_{c}$ \\
\hline$q_{0}^{*}$ & - & $(1+c-\alpha) / 2$ \\
\hline$q_{1}^{*}$ & $\delta(c+\beta+2 \delta) /(1+2 \delta)$ & $\delta(c+\alpha+2 \delta) /(1+2 \delta)$ \\
\hline$r_{0}^{*}$ & $(1+c+\beta+2 \delta(1-2 \delta)) /(2+4 \delta)$ & $(1-c-\alpha)^{2} /(4+8 \delta)$ \\
\hline$\Pi^{*}$ & $(1-c-\beta)^{2} /(4+8 \delta)$ & $(1-c-\alpha)^{2} /(8+16 \delta)+\alpha^{2} /(2-4 \delta)$ \\
\hline$S^{*}$ & $(1-c-\beta)^{2} /(8+16 \delta)$ & \\
\hline \hline
\end{tabular}

Within the domain of Markov strategies, a continuum of equilibria, such as those emerging under supergame settings as a consequence of various folk theorems, is unlikely to arise in our model. Strategies that maintain reputation and implement punishment are non-Markov. If, on the other hand, general strategies are allowed, it is conceivable that strategies which revert between these focal points may well lead to a proliferation of equilibria, as in the cases examined in Bond and Samuelson (1987) and Ausubel and Deneckere (1989). However, it is important to recognize that, since all these focal points are essentially monopoly outcomes, equilibria resulted this way would still maintain the monopolistic nature of the market. It is not clear to us at the moment whether there are other kinds of Markov equilibria, such as those analogous to the class of strong Markov perfect equilibria found by Karp (1996), who assumes homogeneous consumers, no used-goods market and no transaction costs.

\section{Economic Implications of the Model}

In this section, we explore economic implications of the model. Since we are mostly interested in the long run behavior of all players, we will focus our discussion on the focal point.

The Economic Depreciation Rate: Whereas $\delta$ characterizes the physical depreciation of the product, the economic depreciation rate should be defined by the ratio of the used-good 
price to the new good price,

$$
\frac{q_{1}^{*}}{q_{0}^{*}}=\delta \frac{2(c+\beta+2 \delta)}{(1+c)(1+2 \delta)},
$$

provided $\beta<\beta_{c}$. This ratio monotonically increases to $\delta$ as $\beta$ increases to $\beta_{c}$. This implies that when leasing is profitable, the economic depreciation rate is higher than $\delta$ (or used goods retain less value than $\delta q_{0}^{*}$ ). This is due to the fact that leasing results in an active secondary market, raises the supply of used goods and reduces the used-goods price.

Coexistence of Leasing and Selling: One of the interesting insights arising from the model is the explanation of why the producer chooses to lease and sell goods concurrently. The analysis of the model shows that it is the heterogeneity of consumers that provides an opportunity for price discrimination; and price discrimination leads to higher profits when both programs are offered. In other words, there are consumers who like to utilize only new goods in every period (class LL), who would like to utilize both new and used goods (class NU), and who would like to only utilize used goods. On one hand, the secondary market renders the coexistence of all these consumer behaviors possible. On the other hand, customizing prices for individual consumer groups results in a higher profit for the monopolist. This interpretation is very different from what has been seen in typical analyses of the Coase conjecture, where leasing is often regarded as a trick of the monopolist to maintain her monopoly power. A common argument is that by making the lifetime of infinitely durable goods contractually finite, the monopolist forces consumers to repeatedly come back to the market. The underlying force in our model that sustains the concurrent leasing and selling is the comparative advantage the manufacturer has over the consumers in disposing used goods in the secondary market. This sharply contrasts with the one proposed in Desai and Purohit (1998). In their model, the coexistence of leasing and selling is maintained by the two differential depreciation rates of the goods which are leased and sold respectively.

Quantitatively, our model predicts that, if $\beta<\beta_{c}$, the optimal allocation of new goods between leasing and selling should be

$$
P_{\mathrm{LEASE}}^{*}=\frac{2\left(\beta_{c}-\beta\right)}{(1-2 \delta)(1-c-\beta)}, \quad P_{\mathrm{SELL}}^{*}=\frac{\beta(1+2 \delta)}{(1-2 \delta)(1-c-\beta)},
$$

which can be easily derived from Eq.(34).

Market Efficiency: Leasing will help the monopolist increase her profit. We also know that leasing makes those consumers with a high reservation price better off, not only because 
they do not have to incur a higher transaction cost $\alpha$, but also because the monopolist only transfers half of her disposal cost to those consumers (see Eq.(32)). What will leasing do to consumers on average? To answer this question quantitatively, let us compute the aggregate consumer surplus per period at the focal point, which is defined by the area between the thick lines and the horizontal axis in Figure 1. When $\beta<\beta_{c}$, some straightforward algebra yields

$$
S^{*}=\frac{(1-c-\beta)^{2}}{8(1+2 \delta)}+\frac{\beta^{2}}{8(1-2 \delta)} .
$$

This aggregate consumer surplus decreases monotonically to

$$
S^{*}=\frac{(1-c)^{2}}{16}
$$

as $\beta$ increases to $\beta_{c}$. A comparison with Eq.(35) indicates that the optimal profit for the monopolist is twice the aggregate consumer surplus period by period at the focal point. So we see that leasing, when it is profitable to the monopolist, is also beneficial to consumers on average. Therefore, according to this model, leasing is an efficiency improving practice, as opposed to an inefficient, rent seeking practice, ${ }^{19}$ as long as the condition $\beta<\alpha$ holds.

Another way to see the improvement in efficiency is to directly compare the total numbers of consumers who utilize new goods in each period. Due to the clearance condition, this is the same as the numbers of consumers who utilize used goods. In the case with leasing, this number is $(1-c-\beta) /(2+4 \delta)$, whereas in the case without leasing, this number is $(1-c) / 4=\left(1-c-\beta_{c}\right) /(2+4 \delta)$. Thus, there are more consumers who utilize both new and used goods in each period when a leasing program is offered.

Pure Selling versus Pure Leasing: In the existing literature, one often finds that, from the viewpoint of the monopolist, either pure selling dominates pure leasing, or vice verse. It turns out that it is not always the case in our model. Using the result in Table 2, we can easily conclude that when the disposal cost to the manufacturer is sufficiently low, i.e. $\beta<\alpha_{c}$, ( $\alpha_{c}$ is defined in the same table.) pure leasing is better than pure selling. However, when the disposal cost to the manufacturer is too high, i.e. $\beta>\alpha_{c}$, the order is reversed. Furthermore, the parameter window for pure leasing to dominate pure selling is narrower than the window for concurrent selling and leasing to dominate pure selling, since

\footnotetext{
${ }^{19}$ Due to finite durability, the monopoly persists no matter whether the manufacturer uses leasing. Rent seeking here is used in the sense of anti-trust.
} 
$\alpha_{c}<\beta_{c}$. Therefore, whenever pure leasing dominates pure selling, concurrent selling and leasing always dominates $=$ both pure selling and pure leasing.

Producer's Monopoly Power: In many studies of the Coase conjecture, it has been assumed that the durability of the good is infinite. In that case, one typically finds that the monopoly power of the producer has been eroded. The situation in our model is different, i.e., monopoly power is essentially intact, simply due to the fact that the lifetime of the goods is finite. This result is qualitatively similar to that of Bond and Samuelson (1984, 1987) and Karp (1996), who realize that the Coase conjecture fails when durable goods depreciate over time.

We can go one step further by quantifying this effect. The optimal price for selling new good, $q_{0}^{*}=(1+c) / 2$, can be understood as the monopoly price when leasing is not a profitable practice for the manufacturer. When it costs too much to sell a used good $\left(\beta>\beta_{c}\right)$, the monopolist will only induce two classes of consumers: NU and II, a situation essentially equivalent to non-durable goods markets. The profit is then given by $\left(q_{0}-c\right)(1-$ $\left.q_{0}\right) / 2$, since the number of consumers who purchase new goods is $\left(1-q_{0}\right) / 2$ at each period.

Somewhat surprisingly, the monopolist does not change $q_{0}^{*}$ even when leasing is a profitable practice. All she does is to properly pick $r_{0}^{*}$, according to her disposal cost. Intuitively, this behavior can be understood as a combination of several factors. First, consumers in class NU are indifferent between being on $\mathrm{N}$ or $\mathrm{U}$ at any moment, as long as they are sufficiently patient. Second, these consumers do not participate in the used-goods market. Therefore they care little about the values of $\delta, \alpha$ and $\beta$ per se. Third, the populations of class LL and class NU are controlled by two prices that can be independently varied. These conditions also remain unchanged under the situation with scrappage. There we also find the same pricing behavior, i.e., $q_{0}^{*}=(1+c) / 2$. However, when $\rho<1$ the first condition is violated, $q_{0}^{*}$ will no longer be $\delta$ independent. Violation of the third condition can be found in the case when leasing is not allowed, as in Table 2 , where $q_{0}^{*}$ is found to depend on the transaction cost $\alpha$.

Relative Demand Elasticities: Let us now examine the relative demands and their elasticities. We note that $B_{0}$ is negatively sloped in $q_{0}$, whereas leasing a new good and buying a used good act as substitutes to buying a new good. Likewise, $L_{0}$ is negatively sloped in $r_{0}$, whereas buying a new good acts as a substitute for leasing a new good. Since consumers in 
class LL do not utilize used goods at all, the used-good price does not enter the expression for the leasing population directly.

At the focal point of the equilibrium, the relative elasticities of the demand for purchasing new goods and for leasing new goods are respectively given by

$$
\epsilon_{\mathrm{N}}^{*}=-\frac{1+c}{\beta} \quad \text { and } \quad \epsilon_{\mathrm{L}}^{*}=-\frac{1+c+\beta+2 \delta(1-2 \delta)}{\beta_{c}-\beta} .
$$

From these expressions we can see that the market operates in a region of very high relative elasticities. This is mainly due to the substitution effect between buying and leasing new goods, and to a much lesser degree, to the substitution between new and used goods. It is also interesting to note that $\epsilon_{\mathrm{L}}^{*}$ goes to infinity when $\beta \rightarrow \beta_{c}$, reflecting the fact that class LL is about to be squeezed out.

Conditions for Profitably Scrapping Used Goods: Up to now, all off-lease goods are returned to the manufacturer, since strategies, such as LU, are not optimal. As a result, the active trading of all used goods goes through the monopolist. Is it profitable for the manufacturer to scrap some or all of the off-lease goods for a salvage value of $v_{s}$ per unit? If the answer is yes, it is likely to hurt the consumer surplus.

Let us use $x$ to denote the fraction of the off-lease goods that enter the used-goods market. The remaining portion of the off-lease goods, $1-x$, are scrapped by the monopolist. In principle, $x$ can be thought of as a control variable. Here we will only consider the long run limit, or the focal point. The clearance condition in Eq.(26) becomes $x\left(1-\theta_{1}\right)=\theta_{2}-\theta_{3}$ and the used-goods price in Eq.(27) becomes

$$
q_{1}^{*}\left(q_{0}, r_{0}, x\right)=\frac{\delta\left[x(1+\rho) r_{0}-(x-\rho) q_{0}-x \rho(1-2 \delta)\right]}{\rho[1-\delta(1-\rho)]} .
$$

The per period profit function for the monopolist at the focal point becomes

$$
\Pi=\left(q_{0}-c\right) B_{0}+\left(r_{0}-c\right) L_{0}+\left(q_{1}^{*}-\beta\right) x L_{0}+v_{s}(1-x) L_{0} .
$$

The tradeoff here is not just between the revenue from selling used goods and salvage values. The monopolist also hopes to increase the revenues from selling new goods by decreasing the number of used goods, because fewer used goods on the market may raise the demand for new goods, and hence allow her to charge a higher price on these new units.

The search for the region where scrappage is profitable for the monopolist proceeds as follows. The optimal profit is expanded in a Taylor series about $x=1$. Only when the sign 
of the first order coefficient of $(x-1)$ is negative, can scrappage be profitable. Imposing negativity on this coefficient yields the following condition

$$
c-v_{s}<\left(\frac{1-2 \delta}{2}+\frac{\beta}{2 \delta}\right)+\frac{v_{s}}{2 \delta} .
$$

$v_{s}$ on the left of the above inequality is the direct effect from the salvage value. The right hand side of the inequality are the indirect effects related to the revenue increase of new goods and price increase of used goods. This inequality sets a stringent requirement and is not always easy to satisfy in general with realistic parameter values. One either needs the salvage value, $v_{s}$, to be very high or used goods to be worth almost nothing, i.e., $\delta$ close to zero. This result may explain why scrappage is rarely observed in industries such as the automobile industry, in which production costs are high and depreciations are slow. In contrast, in the computer industry, $\delta$ may be very small due to a fast pace of technological innovation. There, scrappage is much more common and the secondary market for used computers is much less vibrant, a situation very similar to that described by Rust (1986) and Waldman (1997).

\section{Conclusions}

We have constructed a model that is based on a relatively realistic setting and assumptions. The model treats consumers as heterogeneous and endogenizes their consumption patterns. It can simultaneously accommodate many commonly observed phenomena or stylized facts. We solved the model by combining Markov perfect equilibrium and general equilibrium in a dynamic game. In addition to solving for the focal point, our framework also allowed us to go beyond the focal point on the equilibrium path and to find out how the focal point can be reached via backward induction.

Microscopically, we showed how consumers, according to their willingness to pay for the good, segment themselves into various consumption classes. The formation of these classes is strongly influenced by transaction costs to sell used goods, as manifested in the non-trivial state dependence of consumers' consumption decisions. Consequently, consumers seek time-consistency in their intertemporal consumption decisions, as the monopolist does. The substitution effects between new and used goods, and between selling and leasing, are highlighted by the significant relative elasticities of demand. 
At the same time, we also showed that the major motivation of the manufacturer to offer a leasing program is price discrimination. Despite this price discrimination, the concurrence of selling and leasing is still Pareto dominant over pure selling or pure leasing alone. This provides a theoretical explanation of the wide spread practice of concurrent selling and leasing. Furthermore, we derived quantitative rules for the monopolist to allocate her goods for leasing and selling. Finally, we showed when the manufacturer can profitably scrap some off-lease goods. Our results reveal that the nature of a durable goods market with one producer and one finitely durable product is essentially monopolistic. The market structure as a whole, constituted by the total demand and supply, prices for new goods and so on, is not significantly different from that of a non-durable goods market.

Many extensions of our model can be envisioned. Even in the monopoly setting, we can make our model somewhat more realistic by extending the lifetime of the product to $N>2$. We can also introduce a substitute product and then study the interactions between the two products and the resulting pricing strategies. An important missing ingredient is hidden information, such as unobservable consumer characteristics and maintenance efforts, unknown product quality, and so on, that causes the problems of moral hazard and adverse selection. A comparative study of the effects due to transaction costs and hidden information could be illuminating. Conceptually, perhaps more interesting directions to take are to generalize the current framework to oligopoly settings, to include demand fluctuations and to treat production capacities as explicit control variables. Confronting the model with empirical data could be another worthwhile effort. 


\section{A Appendices}

\section{A.1 Proofs of Lemma 1}

The argument is almost a transcription of the finite dimensional dynamic programming problem, defined in Eq.(16), which is repeated here for convenience

$$
V_{\theta}[s, p]=\Pi_{\theta}\left[s, R_{\theta}[s, p], p\right]+\rho V_{\theta}\left[R_{\theta}[s, p], p\right] .
$$

The reaction function $R_{\theta}[s, p]$ is chosen to maximize,

$$
U_{\theta}[s, a, p] \equiv \Pi_{\theta}[s, a, p]+\rho V_{\theta}[a, p], \quad \forall s, a \in\{\mathrm{N}, \mathrm{U}, \mathrm{L}, \mathrm{I}\}
$$

with respect to $a$. Since all goods last two periods, a rational consumer, who has a state of either L, U and I (no transaction costs involved), should choose the same action in the current period, provided the price vector is time independent. This immediately implies that at the focal point

$$
R_{\theta}[\mathrm{L}, p]=R_{\theta}[\mathrm{U}, p]=R_{\theta}[\mathrm{I}, p] \equiv R_{\theta}[\overline{\mathrm{N}}, p]
$$

which in turn implies

$$
V_{\theta}[\mathrm{L}, p]=V_{\theta}[\mathrm{U}, p]=V_{\theta}[\mathrm{I}, p] \equiv V_{\theta}[\overline{\mathrm{N}}, p] .
$$

Due to the periodicity of two for all consumption patterns at the focal point, there can be a total of ten distinct classes out of sixteen possible combinations (permutations would not lead to new patterns; for example, NU is regarded the same as UN). We can quickly rule out that the following three patterns: LU, LI, UI, since these would violate Eq.(48).

What remains to be shown is that classes LN and NI can not exist. We will only sketch the proof for class LN below, and the proof for class NI can be done analogously.

If there were a consumer who plays strategy $\mathrm{LN}$, it would mean $R_{\theta}[\mathrm{N}, p]=\mathrm{L}$ and $R_{\theta}[\mathrm{L}, p]=\mathrm{N}$, for some $\theta \in(0,1) .{ }^{20}$ To show this is not possible, we verify that if the consumer plays $R_{\theta}[\mathrm{N}, p]=\mathrm{L}$ once, he will have to follow $R_{\theta}[\mathrm{L}, p]=\mathrm{L}$ from then on, instead of jumping back to $R_{\theta}[\mathrm{L}, p]=\mathrm{N}$. Because the statement $R_{\theta}[\mathrm{N}, p]=\mathrm{L}$ is equivalent to saying that $U_{\theta}[\mathrm{N}, a, p]$ reaches its maximum at $a=\mathrm{L}$, and because $R_{\theta}[\mathrm{L}, p]=\mathrm{L}$ is equivalent to saying that $U_{\theta}[\mathrm{L}, a, p]$ reaches its maximum at $a=\mathrm{L}$, we only need to verify that

$$
U_{\theta}[\mathrm{N}, \mathrm{L}, p]=\max \left\{U_{\theta}[\mathrm{N}, \mathrm{L}, p], U_{\theta}[\mathrm{N}, \mathrm{N}, p], U_{\theta}[\mathrm{N}, \mathrm{U}, p], U_{\theta}[\mathrm{N}, \mathrm{I}, p]\right\}
$$

\footnotetext{
${ }^{20}$ We ignore a measure zero set of $\theta$ values at which indifference occurs.
} 
would imply

$$
U_{\theta}[\mathrm{L}, \mathrm{L}, p]=\max \left\{U_{\theta}[\mathrm{L}, \mathrm{L}, p], U_{\theta}[\mathrm{L}, \mathrm{N}, p], U_{\theta}[\mathrm{L}, \mathrm{U}, p], U_{\theta}[\mathrm{L}, \mathrm{I}, p]\right\}
$$

With the help of Eq.(49) and the explicit form of $\Pi_{\theta}[s, a, p]$ defined in Table 1, it is straightforward to verify that $U_{\theta}[\mathrm{N}, \mathrm{L}, p]>U_{\theta}[\mathrm{N}, a, p]$ indeed guarantees $=U_{\theta}[\mathrm{L}, \mathrm{L}, p]>U_{\theta}[\mathrm{L}, a, p]$ for $a \in\{\mathrm{N}, \mathrm{U}, \mathrm{I}\}$.

\section{A.2 Proof of Lemma 2}

Here we briefly outline the reasons why the monopolist would like to keep the price of leased goods in the interval $\left(q_{0}-q_{1}, q_{0}-q_{1}+\alpha\right)$, as long as $\beta<\beta_{c}$. To be more concise, we confine our analysis to the domain of Eq.(18).

First, when $r_{0}<q_{0}-q_{1}$, NN is dominated by LL, and consumers in class NU will play the strategy LU instead, since they get the same physical utilities and pay less money. However, we know that the reaction functions at the focal point have to be $R_{\theta}[\mathrm{L}, p]=R_{\theta}[\mathrm{U}, p]$, which is inconsistent with the strategy LU. So, when $r_{0}<q_{0}-q_{1}$ the only surviving classes are LL, UU and II, which is equivalent to the case of pure leasing. As shown in Table 2 the profit made by the monopolist in this case is less than that when class NU also exists. Therefore, the monopolist should avoid picking a lease price which is too low.

On the other hand, if the monopolist picks a very high lease price so that $r_{0}>q_{0}-q_{1}+\alpha$, consumers in class LL prefer to play strategy NN, provided the consumer is sufficiently patient. More precisely, strategy NN dominates strategy LL if $\rho$ is greater than $\rho_{c}=$ $\left(q_{0}-r_{0}\right) /\left(q_{1}-\alpha\right),{ }^{21}$ which is a case equivalent to the pure selling examined in Table 2 . Because of the assumption $\beta<\alpha$, consumers' self-replicated leases NN through incurring

\footnotetext{
${ }^{21} \rho_{c}$ is less than one if $r_{0}>q_{0}-q_{1}+\alpha$. To understand the origin of this condition on $\rho$, let us imagine a consumer who leased in the last period and would like to either obey LL or NN from now on. (It would be equally good to assume that the consumer bought a new good in the last period.) The corresponding net present values are $\left[(1-\delta) \theta-r_{0}\right] /(1-\rho)$ and $(1-\delta) \theta-q_{0}+\rho\left[(1-\delta) \theta-q_{0}+q_{1}-\alpha\right] /(1-\rho)$, respectively. Comparison of these two expressions leads to the $=$ condition on $\rho$. How the patterns LL and NN are reached affects the payoff for one period. From L to LLLL $\cdots$ the consumer is already in the long run pattern, whereas from L to NNNN $\cdots$ the consumer's payoff is smaller by $q_{1}-\alpha$ in the current period. Of course, this amount would not matter at all, if the consumer is patient. Therefore, NNNN $\cdots$ will be preferred from the next period on. It is interesting to observe that, if consumers are sufficiently myopic, the payoff from this single period can become critically important. This is a simple example where a single step in history matters in a long run if the patience is extremely low for consumers.
} 
a transaction cost would result in fewer consumers utilizing new goods in every period than LL. As a consequence, the manufacturer's profit would be lowered. Therefore, the manufacturer will try to avoid getting consumers into class NN.

\section{A.3 Approaching the Focal Point}

Armed with the explicit solution of the focal point we can use backward induction to show how the manufacturer should pick the price sequences so that initial states eventually converge to the focal point. To illustrate the idea we consider a special initial condition that has some economic relevance. We choose this initial condition to correspond to the situation where the manufacturer is introducing a new product that has no close substitute available, or $g^{1}(\theta)=(0,0,0,1), \forall \theta \in(0,1)$.

Again, we proceed by construction. Let us assume, without loss of generality, that the focal point is reached at time $t=2$, i.e., $g^{3}(\theta)=g^{*}(\theta)$ and $p^{2}=p^{*}$ (the rest of the notation is illustrated in Figure 2). We will use explicit time labels on various quantities so that the backward induction process is clear. It is important to bear in mind that these labels only indicate the relative timing on the equilibrium path, not any intrinsic time dependence. Let us initially assume that 1 ) all consumers who bought new goods at $t=1$ will hang onto their used goods at $t=2$, and 2) all leased goods at $t=1$ are returned to the manufacturer, who in turn sells all off-lease goods in the used-goods market at $t=2$. These assumptions will be verified at the end of this subsection.

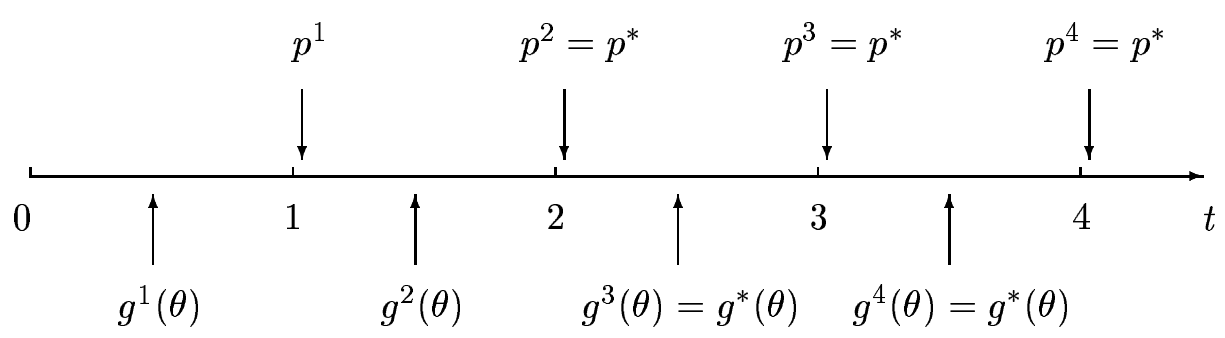

Figure 2: Relative timing of the equilibrium path from the $=$ initial state $g^{1}(\theta)=(0,0,0,1)$ to the focal point $g^{*}(\theta)$.

Since we know by definition that the number of consumers who bought used goods at $t=2$ is given by $B_{1}\left[g^{3}(\theta)\right]=L_{0}^{*}$, the clearance condition at $t=2$ immediately implies that 
the number of consumers who leased new goods at $t=1$ is the same as its counterpart at the focal point: $L_{0}\left[g^{2}(\theta)\right]=1-\theta_{1}^{*}$.

Because the populations of consumers who purchase new goods, lease new goods and purchase used goods at $t=2$ must have their values equal to those at the focal point, the Bellman equation for the manufacturer in this period,

$$
V^{2}\left[g^{2}(\theta)\right]=\max _{q_{0}^{2}, r_{0}^{2}}\left\{\left(q_{0}^{2}-c\right) B_{0}^{*}+\left(r_{0}^{2}-c\right) L_{0}^{*}+\left(q_{1}^{2}-\beta\right) L_{0}^{*}+\rho V^{3}\left[g^{*}(\theta)\right]\right\}
$$

is consistent with the definition $p^{2}=p^{*}$. Furthermore, $V^{2}\left[g^{2}(\theta)\right]$ attains the same maximum value as that at the focal point, since only $L_{0}\left[g^{2}(\theta)\right]=L_{0}^{*}$ enters the equation.

The Bellman equation for a consumer of type $\theta$ at $t=2$ is given by

$$
V_{\theta}^{2}\left[a^{1}(\theta), p^{*}\right]=\max _{a^{2}(\theta)}\left\{\Pi_{\theta}\left[a^{1}(\theta), a^{2}(\theta), p^{*}\right]+\rho V_{\theta}^{3}\left[a^{2}(\theta), p^{*}\right]\right\} .
$$

The maximum solution in $a^{2}(\theta)$, which is a function of $a^{1}(\theta)$, has to have an aggregate consistent with $g^{3}(\theta)=g^{*}(\theta)$. Since the price vector and the continuation are defined to be at the focal point, Eq.(53) actually specifies the aggregate condition that $a^{1}(\theta)$ needs to satisfy so that

$$
g^{*}(\theta)=R_{\theta}^{2}\left[p^{*}\right] \cdot g^{2}(\theta)
$$

This means that $g^{2}(\theta)$ should be able to reach $g^{*}(\theta)$ in one time period through the evolution matrix defined in Eq.(20) at the focal point.

Combining the clearance conditions at $t=1$ and $t=2$ we conclude that the number of consumers who purchase new goods and lease new goods at $t=1$ are the same as that at the focal point, i.e., $B_{0}\left[g^{2}(\theta)\right]=\left(\theta_{1}^{*}-\theta_{2}^{*}\right) / 2$ and $L_{0}\left[g^{2}(\theta)\right]=1-\theta_{1}^{*}$. So far, only the aggregate form of $g^{2}(\theta)$ is constrained.

Because there are no used goods at $t=1$, the explicit Bellman equation for the manufacturer at this period is given by

$$
V^{1}\left[g^{1}(\theta)\right]=\max _{q_{0}^{1}, r_{0}^{1}}\left\{\left(q_{0}^{1}-c\right)\left(\frac{\theta_{1}^{*}-\theta_{2}^{*}}{2}\right)+\left(r_{0}^{1}-c\right)\left(1-\theta_{1}^{*}\right)+\rho V^{2}\left[g^{2}(\theta)\right]\right\} .
$$

The continuation part is again constrained, so the maximization is only on the profit at $t=1$, which in turn implies that the manufacturer would like to make $q_{0}^{1}$ and $r_{0}^{1}$ as high as possible, as long as they are consistent with the consumer behavior at $t=1$

$$
g^{2}(\theta)=R_{\theta}^{1}\left[p^{1}\right] \cdot g^{1}(\theta)
$$


The obvious way to achieve the highest prices possible by the manufacturer is to only induce those consumers who have the highest willingness to pay to lease and buy new goods at $t=1$. So, $a^{1}(\theta)$ should correspond to a $g^{2}(\theta)$ of the form

$$
g^{2}(\theta)= \begin{cases}(0,0,1,0) & \text { when } \theta \in\left(\theta_{1}^{*}, 1\right) \\ (1,0,0,0) & \text { when } \theta \in\left(\bar{\theta}_{2}^{*}, \theta_{1}^{*}\right) \\ (0,0,0,1) & \text { when } \theta \in\left(0, \bar{\theta}_{2}^{*}\right)\end{cases}
$$

where $\bar{\theta}_{2}^{*} \equiv\left(\theta_{1}^{*}+\theta_{2}^{*}\right) / 2$. It is interesting to note that this $g^{2}(\theta)$ would imply, through Eq.(54), another version of $g^{*}(\theta)$ that is different from the one specified in Eq.(28). Here we see the explicit initial state dependence of $g^{*}(\theta)$.

The above consumer behavior is solved from the Bellman equation

$$
V_{\theta}^{1}\left[\mathrm{I}, p^{1}\right]=\max _{a^{1}(\theta)}\left\{\Pi_{\theta}\left[\mathrm{I}, a^{1}(\theta), p^{1}\right]+\rho V_{\theta}^{2}\left[a^{1}(\theta), p^{1}\right]\right\} .
$$

This equation can be used to determine the price vector at $t=1$ by an indifference analysis. First, we note that Eq.(57) and subsequent consumer strategies imply

$$
V_{\theta}^{1}\left[\mathrm{I}, p^{1}\right]= \begin{cases}(1-\delta) \theta-r_{0}^{1}+\rho V_{\theta}\left[\mathrm{L}, p^{*}\right] & \text { when } \theta \in\left(\theta_{1}^{*}, 1\right), \\ (1-\delta) \theta-q_{0}^{1}+\rho \delta \theta+\rho^{2} V_{\theta}\left[\mathrm{U}, p^{*}\right] & \text { when } \theta \in\left(\bar{\theta}_{2}^{*}, \theta_{1}^{*}\right), \\ \rho V_{\theta}\left[\mathrm{U}, p^{*}\right] & \text { when } \theta \in\left(\theta_{2}^{*}, \bar{\theta}_{2}^{*}\right) .\end{cases}
$$

Demanding $V_{\theta_{1}^{*}+\epsilon}^{1}\left[\mathrm{I}, p^{1}\right]=V_{\theta_{1}^{*}-\epsilon}^{1}\left[\mathrm{I}, p^{1}\right]$ and $V_{\bar{\theta}_{2}^{*}+\epsilon}^{1}\left[\mathrm{I}, p^{1}\right]=V_{\bar{\theta}_{2}^{*}-\epsilon}^{1}\left[\mathrm{I}, p^{1}\right]$ yields $r_{0}^{1}-r_{0}^{*}=q_{0}^{1}-q_{0}^{*}$ and $q_{0}^{1}-q_{0}^{*}=(1-\rho) V_{\bar{\theta}_{2}^{*}}\left[\mathrm{U}, p^{*}\right]=\left[(1-\delta) \bar{\theta}_{2}^{*}-q_{0}^{*}+\rho \delta \bar{\theta}_{2}^{*}\right] /(1+\rho)$.

This result has a nice economic interpretation: both prices $q_{0}^{1}$ and $r_{0}^{1}$ are shifted upward, due to lack of the substitution effect from used goods at $t=1$, by a particular amount so that the consumer of type $\theta=\bar{\theta}_{2}^{*}$, or the mid-point person in class NU, is indifferent between buying and not buying a new good at $t=1$. This amount is exactly the average one-period surplus of the same consumer at the focal point.

Finally, let us check the consistency of the assumption made at the beginning of this subsection. Since the focal point is reached at $t=2$ we can use the reaction functions at the focal point starting at $t=2$. Eq.(20) shows that consumers in $\left(\theta_{1}^{*}, 1\right)$ react to $\mathrm{L}$ with $\mathrm{L}$, and that consumers in $\left(\theta_{2}^{*}, \theta_{1}^{*}\right)$ react $\mathrm{N}$ with $\mathrm{U}$. These are consistent with our earlier assumptions. 


\section{References}

[1] Anderson, S. P. and Ginsburgh, V. A. 1994. "Price Discrimination via Second-Hand Markets," European Economic Review, 38, 23-44

[2] Ausubel, L. M. and Deneckere, R. J. 1989. "Reputation in Bargaining and Durable Goods Monopoly," = Econometrica, 57, 511-531.

[3] Bagnoli, M., Salant, S. W., Swierzbinski, J. E. 1989. "Durable-Goods Monopoly with Discrete Demand," J. of Political Economy, 97, 1459-1478.

[4] Bertsekas, D. P. 1995. "Dynamic Programming and Optimal Control," Vol.I, page 307, Athena Scientific, Belmont, Massachusetts.

[5] Bond, E. and Samuelson, L. 1984. "Durable Good Monopolies with Rational Expectations and Replacement Sales," RAND J. of Economics, 15, 336-345.

[6] Bond, E. and Samuelson, L. 1987. "The Coase Conjecture Does Not Hold for Durable Good Monopolies with Depreciation," Economics Letter, 24, 93-97.

[7] Bucovetsky, S. and Chilton, J. 1986. "Concurrent Renting and Selling in a Durable Goods Monopoly Under Threat of Entry," RAND J. of Economics, 17, 261-278.

[8] Bulow, J. 1982. "Durable Goods Monopolies," J. of Political Economy, 90, 314-332.

[9] Coase, R. 1972. "Durability and Monopoly," J. of Law and Economics, 15, 143-149.

[10] Desai, P. and Purohit, D. 1998. "Leasing and Selling: Optimal Marketing Strategies for a Durable Goods Firm," Management Science, 44, S19-S34.

[11] Gul, F., Sonnenschein, H. and Wilson, R. 1986. "Foundations of Dynamic Monopoly and the Coase Conjecture," J. of Economic Theory, 39, 155-190.

[12] Hendel, I. and Lizzeri, A. 1999. "Interfering with Secondary Markets," RAND J. of Economics, 30, 1-21.

[13] Hendel, I. and Lizzeri, A. 1997. "Adverse Selection in Durable Goods Markets," NBER working paper \#6194, Sept. 
[14] Hendel, I. and Lizzeri, A. 1998. "The Role of Leasing under Adverse Selection," NBER working paper \#6577, May.

[15] Huang, S. and Yang, Y. 2000. "Valuing Lease Contracts in Imperfect Durable Goods Markets," Technical Report, Ford Research Lab., August.

[16] Kahn, C. 1986. "The Durable Goods Monopolist and Consistency with Increasing Costs," Econometrica, 54, 275-294.

[17] Karp, L. 1996. "Depreciation Erodes the Coase Conjecture", European Economic Review, 40, 473

[18] Kuhn, K. U. 1998. "Intertemporal Price Discrimination in Frictionless Durable Goods Monopolies," J. of Industrial Economics, 46, 101-114.

[19] Maskin, E. and Tirole, J. 1988. "A Theory of Dynamic Oligopoly, I: Overview and Quantity Competition with Large Fixed Cost," Econometrica, 56, 549-569.

[20] Maskin, E. and Tirole, J. 1988. "A Theory of Dynamic Oligopoly, II: Price Competition, Kinked Demand Curves, and Edgeworth Cycles," Econometrica, 56, 571-599.

[21] Porter, R. H. and Sattler, P. 1999. "Patterns of Trade in the Market for Used Durables: Theory and Evidence," NBER working paper \#7149, May.

[22] Rust, J. 1986. "When Is It Optimal to Kill Off the Market for Used Durable Goods?" Econometrica, 54, 65-86.

[23] Smith, C. and Wakeman, L. 1985. "Determinants of Corporate Leasing Policy," J. of Finance, 15, 895-910.

[24] Stokey, N. 1981. "Rational Expectations and Durable Goods Pricing," Bell J. of Economics, 12, 112-128.

[25] Villas-Boas, J. M. 2000. "Price Cycles in Markets with Customer Recognition," Working paper, Berkeley.

[26] Waldman, M. 1997. "Eliminating the Market for Secondhand Goods: An Alternative Explanation for Leasing," J. of Law and Economics, 40, 61-92. 